\title{
WILL YOU MARRY ME? \\ A PERSPECTIVE ON THE GENDER GAP
}

\author{
Ronel Elul, José Silva-Reus and Oscar Volij
}

WP-AD 97-20

Correspondence to: Ronel Elul. Brown University, Department of Economics, RI 02912 (USA).

Ronel_Elul@Brown.Edu.

Editor: Instituto Valenciano de Investigaciones Económicas, s.a.

Primera Edición Octubre 1997

ISBN: 84-482-1605-9

Depósito Legal: V-4113-1997

IVIE working papers offer in advance the results of economic research under way in order to encourage a discussion process before sending them to scientific journals for their final publication.

\footnotetext{
* We thank L. Corchon, J. Driscoll, R. Friedberg, O. Galor, T. Fujiwara-Greve, D.N. Weil and seminar participants at Brown, Carnegie-Mellon, Stanford (S.I.T.E), and the International Conference on Game Theory at Stony Brook. The hospitality of the Department of Economics at Brown University is gratefully acknowledged, as well as financial support by the D.G.I.C.Y.T under Project PB93-0940 and a mobility grant.
}

** R. Elul and O. Volij: Brown University; J. Silva-Reus: Universidad de Alicante. 


\title{
WILL YOU MARRY ME? A PERSPECTIVE ON THE GENDER GAP
}

\author{
Ronel Elul, José Silva-Reus and Oscar Volij
}

\section{A B S T R A C T}

This paper develops a general equilibrium model of the gender wage up. The difference in earnings is a consequence of a demographic regularity -that men tend to marry younger women- which limits women's labor mobility. However, couples are always free not to marry, and do so only if it is in each's self-interest.

In our model, marriage is beneficial because the joint consumption is a household public good. The intrafamily allocation of resources is determined via noncooperative bargaining; this leads to interesting interactions between the game played by husband and wife on the other hand, and the competitive environment in which they are immersed on the other. One example of this is the gender gap.

KEY WORDS: Gender Gap; Bargaining Household Models; Overlapping Generations. 


\section{Introduction}

The aim of this paper is to develop a model which explains the gender gap - that is, the observed difference in wages between men and women. We model this difference as being the outcome of a process whereby individuals endogenously choose their occupations, and not as the result of any intrinsic difference between the sexes, nor of discrimination. This does not mean that we do not believe that such differences (or discrimination, for that matter) do not exist, or are insignificant; we are only interested in showing that it is possible to explain the gender gap without appealing to them.

We base our explanation on a demographic fact - that men tend to marry younger women, and show how this can result in an observed gender gap. 1 This is the only distinction which we posit between men and women. As a result of this difference, however, men choose their occupation before their potential spouses do, and so married women are left with less flexibility in their choice of occupation, with consequent lower income on average. Yet all of this occurs endogenously; women are not required to marry, and in fact do so only when it proves beneficial to them. This explanation of the gender gap is consistent with two empirical regularities: firstly that the wage gap is greatest between married men and women, and, second, that differences in earnings between men and women are rarely reflected in overt and explicit discrimination, in which a woman receives a lower salary for doing precisely the same work, but rather in a more subtle form involving sorting across occupations. ${ }^{2}$

We begin with a simple rational-expectations general equilibrium model with overlapping generations as in Diamond (1965). We now assume that there are two cities, denoted city I and city II. As we will see, these cities will represent specialization in the labor markets. In each period, a continuum of men and women are born in each city. Each agent lives for two periods and is endowed with one unit of labor when young. The labor

\footnotetext{
${ }^{1}$ This assumption is discussed below.

${ }^{2}$ C.f. Gunderson (1989) for a summary of the empirical evidence on the gender gap.
} 
endowment of the individuals can be of one of two types. One unit of labor of type I is equivalent to one efficiency unit in city I, while it represents only $\beta$ efficiency units when applied to city II. Analogously, one unit of type II labor is equivalent to only $\beta$ efficiency units in city I, while it represents one unit if used in city II. These differences in productivity are reflected in the wage received by each type of labor in each city; this wage is set competitively, so as to equate the supply and demand for labor. It is important to note, however, that workers always have the opportunity to react to inter-city wage differentials by moving from one city to the other.

In this model, $\beta$ represents the degree of firm-specificity of labor. For example, each city may use a different language, and a worker will be able to obtain the best job only by being fluent in that language, otherwise he or she will be less productive in that city. Another way to view $\beta$ is as representing some unmodeled investment in human capital which is specific to one type of firm or industry.

To this economic framework, we add the aforementioned constraint — that men marry younger women. Note that this is not an intrinsic difference but rather a sociological one. It is modeled in the following manner. A man born in a particular period knows that in the following period he will be randomly matched to a woman born in that period. Thus he has only a $50 \%$ chance of being matched to a woman of the same type, and he makes his consumption and saving decisions with this in mind. Modeling individuals as not choosing their partners may be seen as representing the fact that it is difficult (if not impossible!) to choose with whom to fall in love. Although this matching is itself free of economic considerations, we will see that the decision to marry is not.

The life-cycle now proceeds as follows. Since they are born unwed and do not have any information about their potential match, the men maximize their income by moving to the appropriate city. They then work in their youth, consume some of their earnings while young, and save the rest for their old age, all without knowing the type of the woman to whom they will be matched. In the next period, the men all propose marriage to their match. The sole benefit accruing to marriage is that the consumption which takes place 
during their single period of life together is a (household) public good for the couple. ${ }^{3}$ Consequently, a higher level of joint utility can be achieved for a given expenditure. At worst, men are indifferent to marriage, and may benefit from it if they are fortunate enough to marry a woman who does not want to save all of her income. Thus, as we will see, a man may well want to save more than he otherwise would in order to encourage a woman to marry him.

Now consider the model from the perspective of a representative woman. As soon as the woman is born, she is randomly matched to a man from the previous generation. She must then decide whether to marry her match, and also how much to save and how much to contribute towards today's consumption - that is, the household public good. If she is matched to a man of her own type, then the benefits of marriage are clear and she will certainly accept the man's proposal. If, however, she is matched to someone living in a city of a type different from her own, then she faces a dilemma: she must either marry and receive a salary corresponding to her lower productivity, or she may choose to reject the offer and instead go to work in the city of her type for a higher wage; unfortunately, in this case she will relinquish the benefits of marriage and all of her consumption will be purely private. Her choice will depend on the terms of her husband's offer (that is, his savings) as well as other factors like wages and interest rates. If what he has saved is large enough relative to the opportunities she gives up by marrying him, then she will marry, otherwise she will not. It is then not hard to see that a gender gap will occur when some women choose to marry even though by doing so they lower their (private) wage.

Note that all agents, be they men or women, choose their city of lifetime residence in their first period of life. The only difference is that the men do so without knowing to whom they will be matched, whereas the women already have this information when they are young. In this model, individuals cannot relocate in their second period of life, even though they work only in the first period; this assumption is made for the sake of

\footnotetext{
${ }^{3}$ C.f. Manser and Brown (1980) and McElroy and Horney (1981), who emphasize the public good character of (shared) consumption within the family as an economic benefit of marriage.
} 
simplicity. One can conceive, however, of a more elaborate model in which agents can move at any time, work in both periods of life, and become more productive by remaining at a single job. Such a model would yield similar results, but at the cost of far greater complexity.

In this model, individuals are utility maximizers, and choose to marry only when it is in their self-interest. We need, however, to specify the mechanism by which a married couple decides on the level of their joint consumption. Although there are potential benefits from marriage, the spouses do not have common interests. The husband, on the one hand, wants to consume as much as possible in this last period of his life, while the wife would like to save some income for her lonely future. As a result, they must bargain over the level of their joint consumption. ${ }^{4}$

There are several ways to model this. We take the extreme position of endowing the women with all the bargaining power. This means that the intrafamily division between joint consumption and saving (for the woman's lonely future) can be seen as the outcome of an ultimatum game. More precisely, although it is the man who brings his savings and proposes marriage to the woman, and therefore has a first-mover advantage, the woman is in fact the one who sets the ultimatum, in the form of the contribution the man anticipates she will make to their joint consumption.

The outline of the paper is as follows. Sections 2 and 3 briefly discusses the related literature. In Section 4 we develop the model. Sections 5 and 6 discuss the notion of equilibrium used in this paper. Section 7 then presents some numerical examples. The main results of the paper are presented in graphical form in Section 8. Finally, Section 9 gives the proof of existence of equilibrium.

\footnotetext{
${ }^{4}$ The notion that bargaining takes place within the family has penetrated even the popular literature. For instance, Mahony (1995) writes, “... negotiation takes place every day in every family. It may be spoken, unspoken, or even unconscious. "
} 


\section{Demographic Underpinnings}

One key assumption underlying this paper is the existence of an age gap between husband and wife. This assumption is supported by strong empirical evidence; it can be observed in all countries, exceeding ten years (on average) in some. ${ }^{5}$ In the case of United States, the difference in median ages of first marriage was 1.8 years in $1988 .{ }^{6}$ For the mechanism of our model to apply, the actual length of the age gap need not be very large - all that is required is that the man have a small head-start in his career. ${ }^{7}$

Although we assume it, there are of course several possible explanations for the existence of an age gap. The reader can conceive of biological or evolutionary reasons for why a man might "want" a younger woman, or vice-versa. There are also economic explanations for this phenomenon; see, for example, Bergstrom and Bagnoli (1993).

In our model, agents choose their city of residence when young. As a result, the aforementioned age gap implies that a woman's decision as to where to live is tied directly to the decision as to whether to marry or not. This has testable implications, which are supported by empirical evidence. For example, if one treats the agents as being born in the city of their own type (i.e. in which their wage is maximized), then the model would predict that the only migrants are women who move to marry. This is indeed the case for rural India; as Rosenzweig and Stark (1989) point out, "approximately 80 percent of ... 'lifetime migrants' were women who gave marriage as the principal reason for their move. Migration in India is thus predominantly a marital phenomenon ...." Alternatively, one could assume that agents are randomly born in cities, in which case the model predicts that (if an equilibrium gender gap exists) the migration of men is more likely to increase their wage than that of women. This results from the fact that while male migrants are always moving in order to increase their wage, women sometimes move in order to follow

\footnotetext{
${ }^{5}$ C.f. Patterns of First Marriage: Timing and Prevalence (1990).

${ }^{6}$ C.f. Statistical Abstract of the United States (1995).

${ }^{7}$ For example, a model in which individuals live for one hundred and twenty periods, and men marry women who are two periods their junior would yield similar results to this paper's.
} 
their mate (thereby increasing their utility, although not necessarily their wage). This is supported by Mincer (1978), who finds that married women are the least likely to derive economic benefit from family migration. More recent evidence can be found in Payne and Warner (1992) and, for Malaysian data, in Chattopadhyay (1996).

\section{Relation to the Literature}

This paper is by no means the first to study the question of the gender gap. Unlike our paper, most of the literature assigns some exogenous advantage to men over women. For example, in Galor and Weil (1996) men are endowed with two types of labor, physical and mental, while women have only mental labor. In others, although the gender gap is the result of discrimination, meaning that it does not reflect lower marginal productivity on the part of women, it is nevertheless facilitated by some exogenous difference. For example, in Rothschild-Stiglitz (1982) women have noisier signals and thus receive a lower wage. Similarly, in segmented labor market models such as Goldin (1986), women have shorter working lives, and it is thus more difficult to monitor them - therefore they are less likely to be candidates for efficiency-wage jobs.

Two other papers are closer in spirit to our work. In Francois (1996) there are two symmetric equilibria - in one only men get efficiency wage jobs (which pay a higher wage) while women do not, while in the other the roles are reversed. This discrimination is a coordinated response to the fact that if both members of a couple hold efficiency wage jobs then they will be likelier to shirk. In Lazear and Rosen (1990) women are promoted less readily than men (and thus earn less on average), because they have an advantage in extra-market production and hence are likelier to leave the workforce.

Similarly, in our approach the difference between men and women is not necessarily an advantage accruing to the men. More precisely, although the men have a first-mover advantage, the women have the ultimatum power. There is no a priori reason for one to always dominate the other, and in fact, depending on the parameter values, either the man 
or the woman can be better-off in equilibrium.

The other strand of the literature to which our paper relates is that of bargaining within the family. The roots of this approach are in Manser and Brown (1980) and McElroy and Horney (1981), who applied the Nash bargaining solution to analyze marriage and divorce; this literature is ably surveyed by Bergstrom (1995). ${ }^{8}$ One recent example of this literature is Echevarria and Merlo (1995), which uses a combination of OLG and Nash bargaining between husband and wife to present a dynamic explanation of the gender differences in education of children. In our paper we have chosen, however, not to use a Nash bargaining model, nor Rubinstein-style bargaining, ${ }^{9}$ but have rather modeled the decision-making process as an ultimatum game. We choose this form both for its simplicity and, more importantly, for the fact that it puts all of the bargaining power into the hands of the woman. Although this then results in a higher utility for the woman, it also decreases the pressure on her to maximize her wage, and so actually leads, ceteris paribus, to a higher wage gap.

It is important to point out that, with the exception of Galor and Weil (1996), the aforementioned models all take a partial equilibrium approach to the question of the gender gap. As we will see, in our model the very existence of a gender gap, and its consequences for welfare, depend critically on the relationship between wages and interest rates; thus taking these to be fixed seems to us to be flawed.

\section{The Model}

\subsection{The Technology $-A$ Tale of Two Cities}

We begin with the description of the technology.

There are two firms (firm I and firm II), located in two different cities (city I and city

\footnotetext{
${ }^{8}$ It is also currently the subject of considerable empirical research - for example, Engers and Stern (1996).

${ }^{9}$ C.f. Bergstrom (1995).
} 
II). Each has the same production function $F(K, L)$, where $L$ represents efficiency units of labor and $F$ is homogeneous of degree 1 . The only difference between the firms is in the manner by which they transform physical labor into efficiency units.

There are two types of labor. Type I labor is more efficient in city I, while type II is more efficient in city II. In particular, firm I would obtain $L^{I}+\beta L^{I I}$ efficiency units from the use of $L^{I}$ units of type I labor and $L^{I I}$ units of type II labor, while firm II would obtain $L^{I I}+\beta L^{I}$ efficiency units, where $1 / 2 \leq \beta \leq 1$.

For capital stock $K$ and efficiency units of labor $L$, we let $k=K / L$ denote the capital stock per efficiency units of labor, and define

$$
f(k)=F(k, 1) .
$$

Let $k^{i} \quad(i=I, I I)$ denote the (per-efficiency unit) capital stock demanded by firm $i$. Notice that full mobility of labor and capital ensures that the price of an efficiency unit of labor and of capital will be constant across cities. Therefore, profit maximization and price-taking behavior on the part of firms implies that, for each firm $i$ (located in city $i$ ), we have:

$$
f^{\prime}\left(k^{i}\right)=r
$$

and

$$
f\left(k^{i}\right)-k^{i} f^{\prime}\left(k^{i}\right)=w
$$

where $w$ is the wage rate paid per efficiency unit of labor and $r$ is the rental rate of capital, assuming full depreciation of capital.

These equations imply, in fact, that each firm has the same demand for capital (per efficiency units of labor), which we denote by $k$. 


\subsection{Individuals and their Marriage Games}

$$
\text { לא-טוב היות הארם לבדו, אעשוֹ-לו עזר כנגדו } 10
$$

In every period $t$, a set of individuals with mass 1 is born. Each individual lives for two periods and has identical preferences, given by the utility function

$$
u\left(c_{t}, c_{t+1}\right)=\ln \left(c_{t}\right)+\ln \left(c_{t+1}\right)
$$

where $c_{t}$ is the consumption of the individual when young, and $c_{t+1}$ when old.

Individuals within a generation are classified into four categories, each of which encompasses a population of measure $1 / 4$.

Half of the generation $t$ is born with one unit of labor of type I while the other half is born with one unit of labor of type II. We will term these agents "type I" and "type II", respectively. Labor can be used only when young and we assume that there is no utility accruing to leisure, so agents will want to sell all of their labor endowment.

In addition, half of each of these types are men and the other half are women. Thus the distribution of types within a generation may be summarized by the following table.

\begin{tabular}{l|cc}
\multirow{2}{*}{ Gender } & \multicolumn{2}{|c}{ Labor Type } \\
\cline { 2 - 3 } & Type I & Type II \\
\hline Male & $1 / 4$ & $1 / 4$ \\
\hline Female & $1 / 4$ & $1 / 4$ \\
\hline
\end{tabular}

As we have already discussed, the only difference between male and female is institutional and consists of the constraint that men are allowed to marry only younger women (one at most). Marriage within a generation is not permitted and old women are also not allowed to marry young males. We take this pattern of behavior as exogenously given.

\footnotetext{
${ }^{10}$ For the purposes of this paper this quotation, taken from Genesis 2:18, may be translated as "It is not good for man to be on his own, let us make a helpmate to stand against him." This follows the exegetical explanation of the verse: "If he is fortunate - she will be a helpmate, but if he is not - then she will stand against him in conflict." (רשט)
} 


\subsubsection{The Marriage Game}

The best way to clarify the interaction between the agents is to focus attention on the three periods of a representative couple's life. For this purpose consider the following game of perfect information and chance moves, ${ }^{11}$ which is depicted in Figure 1.

There are three periods in each couple's life. In period 1, the man is born and works, earning a wage $w_{1}$. He must then decide how much of this income to save for period 2 . We denote this saving by $s^{M} .12$

In the following period (period 2), the man is randomly matched to a woman born in this period to whom he proposes marriage. With probability $\frac{1}{2}$, the woman is of his own (labor) type, and with probability $\frac{1}{2}$ she is of the other type. This leads to two separate subgames, differing only in the woman's labor income when married. We denote this income by $I^{S}=w_{2}$ if they are of the same type, and $I^{D}=\beta w_{2}$ when they are of different types.

In each subgame, the woman responds by either accepting or rejecting the man's proposal. If the woman rejects the man's offer, then they live separate lives and he consumes only his savings $s^{M}$, with accumulated interest. This gives him a utility for this second period of his life of $\ln \left(s^{M} r_{2}\right)$. The woman, on the other hand, earns $w_{2}$ (regardless of her type). It is easy to see that the optimal behavior for the woman is thus to split this income equally between consumption (in period 2) and savings (for period 3), so that she receives a utility of $\ln \left(\frac{w_{2}}{2}\right)+\ln \left(\frac{w_{2}}{2} r_{3}\right)$.

If the woman accepts the man's marriage proposal, however, then she decides how to divide their resources between joint consumption $c^{i}$ and savings for the future $s^{i}$, where $i=S, D$. This decision is subject to the constraint that the joint consumption be no less than what the man could achieve on his own, that is, his savings $s^{M}$ plus any accumulated

\footnotetext{
${ }^{11}$ C.f. Osborne and Rubinstein (1994).

${ }^{12}$ Note that we have defined the rental rate of capital so that $\$ 1$ saved by an individual will return $r$ in the following period.
} 


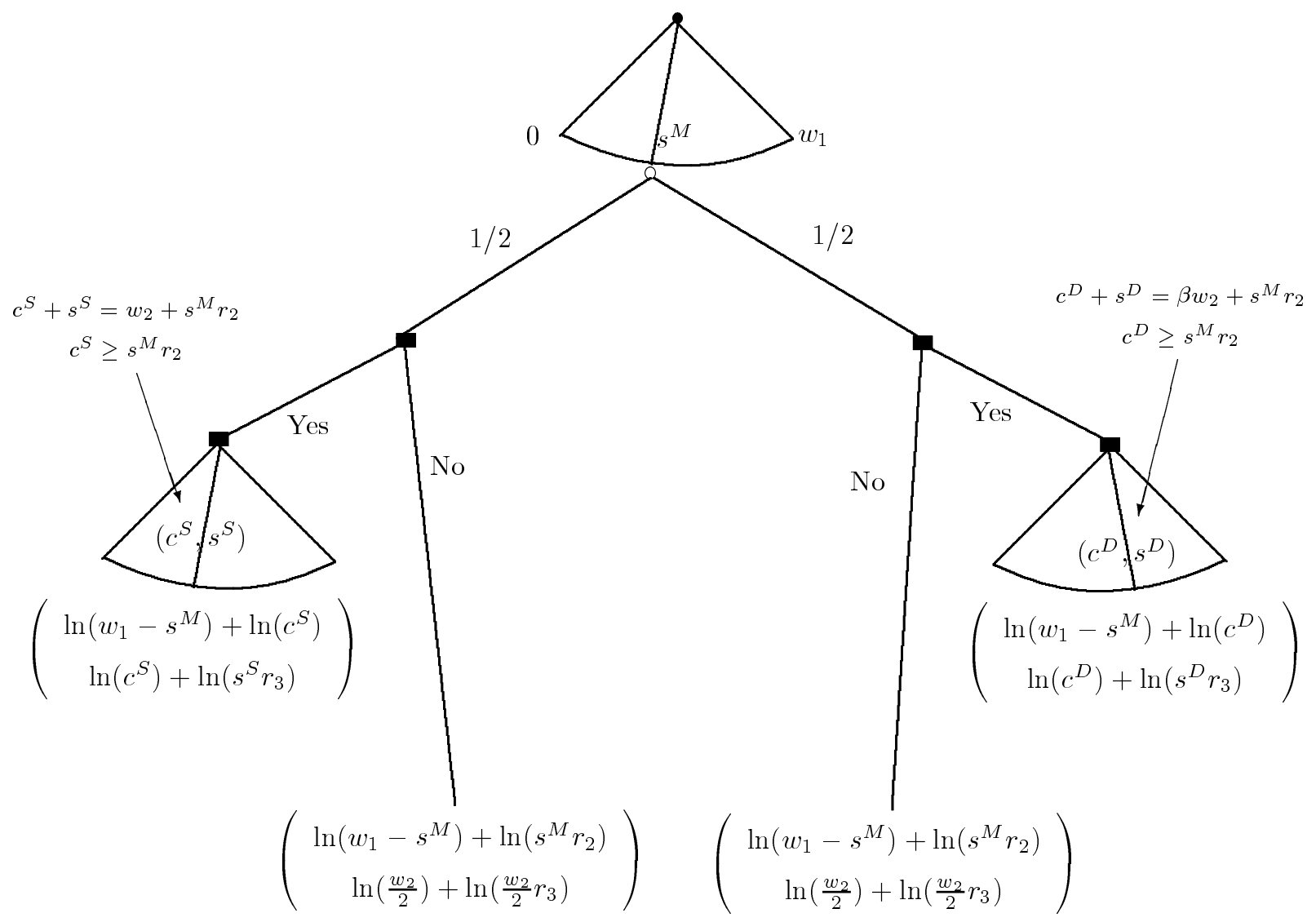

- Man's Decision Node

- Nature's Node

- Woman's Decision Node

Figure 1: The Marriage Game 
interest. 13 For a consumption-savings pair $\left(c^{i}, s^{i}\right)$ satisfying this condition, the man receives utility $\ln \left(c^{i}\right)$ while the woman receives $\ln \left(c^{i}\right)+\ln \left(s^{i} r_{3}\right)$. The determination of this pair properly belongs to the specification of the solution concept, which we now discuss.

\subsubsection{The Solution Concept}

We look for a subgame perfect Nash equilibrium (SPE) of this marriage game. That is, the solution must induce a Nash equilibrium on each subgame. As usual, we determine this solution by working backwards. That is, we first determine the utility levels both when the couple marry and when they do not. Based on this, we next analyze the woman's decision — whether or not to marry - given the man's savings. Finally, we determine the man's optimal savings and thus the subgame perfect equilibrium outcome of the game.

We have already seen that when the couple do not marry, then the man consumes $s^{M} r_{2}$ in the second period of his life, giving him a utility level of $\ln \left(s^{M} r_{2}\right)$. The woman, on the other hand, splits her wage $w_{2}$ between consumption and saving for the future, giving her utility $\ln \left(\frac{w_{2}}{2}\right)+\ln \left(\frac{w_{2}}{2} r_{3}\right)$.

In case the couple does marry, however, then the rules of the game specify that the woman choose the division $\left(c^{i}, s^{i}\right)$ of the joint income, subject to the aforementioned constraints. Given the man's savings $s^{M}$, her optimal decision is the solution $\left(c^{i}, s^{i}\right)$, for $i=S, D$, to the following problem:

$$
\begin{aligned}
\max \ln \left(c^{i}\right) & +\ln \left(s^{i} r_{3}\right) \\
\text { s.t. } \quad c^{i} & \geq s^{M} r_{2} \\
c^{i}+s^{i} & =I^{i}+s^{M} r_{2} .
\end{aligned}
$$

It can be seen that the solution to this problem is:

\footnotetext{
${ }^{13}$ Alternatively, we could have dropped this restriction and allowed the man in turn to either accept or reject the woman's proposed division.
} 


$$
\begin{aligned}
& c^{i}=\left\{\begin{array}{lll}
\frac{I^{i}+s^{M} r_{2}}{2} & \text { if } s^{M} r_{2}<I^{i} \\
s^{M} r_{2} & \text { if } \quad s^{M} r_{2} \geq I^{i}
\end{array}\right. \\
& s^{i}=\left\{\begin{array}{lll}
\frac{I^{i}+s^{M} r_{2}}{2} & \text { if } & s^{M} r_{2}<I^{i} \\
I^{i} & \text { if } & s^{M} r_{2} \geq I^{i}
\end{array}\right.
\end{aligned}
$$

Note that this solution takes one of two forms, depending on the relationship between the man's savings $s^{M}$ and his wife's income $I^{i}$. If the man's savings are sufficiently large (in fact, if the future value of his savings $s^{M} r_{2}$ exceeds the woman's income $I^{i}$ ) then the woman will not contribute anything to their joint consumption and will free-ride. Otherwise, she will contribute a positive amount, and both will strictly benefit from marriage.

Having specified the outcomes both in the case where the couple marries and when they live separately, we can now analyze the marriage decision itself. The woman will certainly accept the marriage proposal when the utility accruing to marriage exceeds that of remaining single. We make the further assumption that when the woman is indifferent, she chooses to marry. ${ }^{14}$

If the man and the woman are of the same type, then it is immediate that she accepts the proposal, since $s^{M} \geq 0$ and she does not give up anything by marrying. When they are not of the same type, however, the woman faces a dilemma. Should she opt for the higher wage which she would receive if she did not marry and lived instead in the other city, or should she take advantage of the benefits accruing to marriage, namely the opportunity to share in the man's savings? In fact, she will choose to marry if the man's contribution

\footnotetext{
${ }^{14}$ In fact, this assumption is not strictly necessary, since it can be shown that there cannot be a subgame perfect equilibrium in which on the equilibrium path the woman is indifferent to marriage and yet she chooses not to marry.
} 
is large enough to compensate the drop in salary which she incurs by marrying, that is, if $s^{M} r_{2} \geq(1-\beta) w_{2}$.

Hence, given the man's saving $s^{M}$, his second period consumption when matched to a woman of the same type is given by:

$$
c^{S}\left(s^{M}, w_{2}, r_{2}\right)=\left\{\begin{array}{lll}
\frac{w_{2}+s^{M} r_{2}}{2} & \text { if } s^{M} r_{2}<w_{2} \\
s^{M} r_{2} & \text { if } \quad s^{M} r_{2} \geq w_{2}
\end{array}\right.
$$

The woman's corresponding savings is:

$$
s^{S}\left(s^{M}, w_{2}, r_{2}\right)=\left\{\begin{array}{lll}
\frac{w_{2}+s^{M} r_{2}}{2} & \text { if } s^{M} r_{2}<w_{2} \\
w_{2} & \text { if } s^{M} r_{2} \geq w_{2}
\end{array}\right.
$$

Similarly, if the man is matched to a woman of the opposite type, then his second period consumption and the woman's savings are given, respectively, by:

$$
c^{D}\left(s^{M}, w_{2}, r_{2}\right)= \begin{cases}s^{M} r_{2} & \text { if } s^{M} r_{2}<(1-\beta) w_{2} \\ \frac{\beta w_{2}+s^{M} r_{2}}{2} & \text { if }(1-\beta) w_{2} \leq s^{M} r_{2} \leq \beta w_{2} \\ s^{M} r_{2} & \text { if } \beta w_{2}<s^{M} r_{2}\end{cases}
$$

and

$$
s^{D}\left(s^{M}, w_{2}, r_{2}\right)= \begin{cases}w_{2} / 2 & \text { if } s^{M} r_{2}<(1-\beta) w_{2} \\ \frac{\beta w_{2}+s^{M} r_{2}}{2} & \text { if }(1-\beta) w_{2} \leq s^{M} r_{2} \leq \beta w_{2} \\ \beta w_{2} & \text { if } \beta w_{2}<s^{M} r_{2}\end{cases}
$$


Note that when the woman contributes nothing, the man's second period consumption is precisely equal to his savings (plus accumulated interest). This can occur either if he saves so little that the woman rejects the proposal (when she is of a different type), or if he saves so much that, although they marry, the woman free-rides.

Having determined the solution to the (woman's) subgames, it remains to calculate the man's optimal saving. Note that he chooses his savings without knowing which type of woman he will be matched to; of course, he knows what to expect from each type.

That is, the man must choose his savings $s^{M}$ so as to maximize his expected utility

$$
\ln \left(w_{1}-s^{M}\right)+\frac{1}{2} \ln \left(c^{S}\right)+\frac{1}{2} \ln \left(c^{D}\right),
$$

where $c^{S}=c^{S}\left(s^{M}, w_{2}, r_{2}\right)$ and $c^{D}=c^{D}\left(s^{M}, w_{2}, r_{2}\right)$ were calculated above by solving the woman's subgame. We denote the set consisting of the man's optimal solutions to this problem by $s^{M}\left(w_{1}, w_{2}, r_{2}\right)$.

The man's problem always has a solution, which is generally unique. One can show that this solution may be of four types.

Case 1 If his optimal savings is greater than $\frac{w_{2}}{r_{2}}$, then the couple always marries and the woman will always free ride, contributing nothing to their joint consumption.

Case 2 If his savings satisfies $\frac{\beta w_{2}}{r_{2}} \leq s^{M} \leq \frac{w_{2}}{r_{2}}$, then they will still always marry, and when the man and woman are of the same type she will contribute (whereas if they are not of the same type then she will not contribute).

Case 3 If his savings satisfies $\frac{(1-\beta) w_{2}}{r_{2}} \leq s^{M}<\frac{\beta w_{2}}{r_{2}}$, the couple will always marry and the woman will always contribute to the joint consumption.

Case 4 Finally, if his savings is less than $\frac{(1-\beta) w_{2}}{r_{2}}$, then they only marry if they are of the same type. In this case, the woman will contribute to joint consumption.

In fact, the man's problem can be interpreted as follows. For each case, the man has a separate optimization problem, determined by an inequality which his savings must satisfy. 
What makes this decomposition interesting is that these cases correspond to different modes of behavior on the part of the women, and thus to four relatively simple optimization problems. He solves each of these sub-problems, and then chooses the case which gives him the highest utility. This gives him his optimal saving.

\section{Competitive Equilibrium}

We look for a steady state equilibrium of the economy, in which markets clear, firms maximize profits and couples play a subgame perfect Nash equilibrium of their respective marriage games. Note that this solution concept differs from the classical competitive equilibrium only in that rather than simply individually maximizing their utilities, agents instead play a subgame perfect Nash equilibrium of their two-person marriage game. While the agents do indeed take prices as given, the consumption-savings decision in the context of the family is modeled as a two-person problem; that is, as a game.

Definition: A steady-state pure equilibrium is a pair $(w, r)$ of (efficiency) wage rate and capital rental rate such that:

$(i)$

$$
k= \begin{cases}\frac{2}{3+\beta} s^{M}+\frac{1}{3+\beta}\left(s^{S}+s^{D}\right) & \text { if } s^{M} r \geq(1-\beta) w \\ \frac{1}{2} s^{M}+\frac{1}{4}\left(s^{S}+s^{D}\right) & \text { if } s^{M} r<(1-\beta) w\end{cases}
$$

where

(ii)

$$
\begin{aligned}
r & =f^{\prime}(k) \\
w & =f(k)-k f^{\prime}(k)
\end{aligned}
$$

and 
(iii)

$$
\begin{aligned}
& s^{M} \in s^{M}(w, w, r) \\
& s^{S}=s^{S}\left(s^{M}, w, r\right) \\
& s^{D}=s^{D}\left(s^{M}, w, r\right)
\end{aligned}
$$

Condition (iii), first of all, requires that agents' decisions be consistent with a subgame perfect Nash equilibrium of their respective marriage games. Condition (ii) is the usual profit-maximizing condition for firms.

As for condition (i), market-clearing, this requires that the level of investment be equal to the aggregate saving in the economy, per efficiency unit of labor. If $s^{M} r \geq(1-\beta) w$, then as we have already seen, the couple always marries, regardless of whether they are of the same type or not. In this case, each man contributes one efficiency unit of labor, each woman who is of the same type as her husband contributes one unit as well, and each woman who is of the opposite type to her husband contributes $\beta$ efficiency units of labor. Since men make up one half of the individuals alive in each period, and each type of woman makes up one-fourth, the total efficiency units of labor supplied amounts to:

$$
\frac{1}{2}+\frac{1}{2}\left(\frac{1}{2}+\frac{\beta}{2}\right)=\frac{3}{4}+\frac{\beta}{4} .
$$

Therefore, per efficiency unit, the total saving is:

$$
\frac{1}{2} \frac{s^{M}}{\left(\frac{3}{4}+\frac{\beta}{4}\right)}+\frac{1}{2}\left(\frac{\frac{1}{2} s^{S}+\frac{1}{2} s^{D}}{\left(\frac{3}{4}+\frac{\beta}{4}\right)}\right)=\frac{2}{3+\beta} s^{M}+\frac{1}{3+\beta}\left(s^{S}+s^{D}\right) .
$$

When $s^{M} r<(1-\beta) w$, by contrast, we know that a couple marry only when they are of the same type. So each agent supplies one efficiency unit and hence the total efficiency supply of labor is one. In this case the market clearing conditions are straightforward. 


\section{Mixed Equilibrium}

As we have defined it, pure equilibrium entails each man behaving in the same manner. We now generalize this to the concept of mixed equilibrium, allowing for heterogeneity in male behavior. In order to obtain this heterogeneity, we must take advantage of the fact that for certain wage and interest rates, there are two subgame perfect equilibria of the marriage game, between which the men are indifferent. As a result, we can have a certain fraction of the population play according to one of these equilibria, and the rest play according to the other.

As we shall see, allowing for this heterogeneity may be necessary in order to ensure the existence of equilibrium. In addition, the mixed equilibria smooth the abrupt transitions in behavior between the cases, so that they become continuous.

Definition: A steady state mixed equilibrium is a pair $(w, r)$ of (efficiency) wage rate and capital rental rate, a pair of cases $i \neq j \in\{1, \ldots, 4\}$, and corresponding weights $\lambda_{i}+\lambda_{j}=1$ such that:

(i)

$$
k= \begin{cases}\frac{2}{3+\beta}\left(\lambda_{i} s_{i}^{M}+\lambda_{j} s_{j}^{M}\right)+\frac{1}{3+\beta}\left(\lambda_{i}\left(s_{i}^{S}+s_{i}^{D}\right)+\lambda_{j}\left(s_{j}^{S}+s_{j}^{D}\right)\right) & \text { if } i, j \in\{1,2,3\} \\ \frac{2}{3+\lambda_{4}+\left(1-\lambda_{4}\right) \beta}\left(\lambda_{i} s_{i}^{M}+\lambda_{j} s_{j}^{M}\right)+\frac{1}{3+\lambda_{4}+\left(1-\lambda_{4}\right) \beta}\left(\lambda_{i}\left(s_{i}^{S}+s_{i}^{D}\right)+\lambda_{j}\left(s_{j}^{S}+s_{j}^{D}\right)\right) & \text { otherwise }\end{cases}
$$

where

(ii)

$$
\begin{aligned}
& r=f^{\prime}(k) \\
& w=f(k)-k f^{\prime}(k)
\end{aligned}
$$

and

(iii) For $\ell=i, j$ : 
- $s_{\ell}^{M} \in s^{M}(w, w, r)$ is defined to be the man's subgame perfect equilibrium savings when he plays according to case $\ell$.

- $s_{\ell}^{S}=s^{S}\left(s_{\ell}^{M}, w, r\right)$.

- $s_{\ell}^{D}=s^{S}\left(s_{\ell}^{M}, w, r\right)$.

The interpretation of this definition is as follows. Given the equilibrium wage and rental rates $(w, r)$, there are two subgame perfect equilibria of the marriage game, between which the man is indifferent. In the first subgame perfect equilibrium, the optimal savings of the man is $s_{i}^{M}$, which places them in the province of case $i$; the best response of the woman is then to save $s^{S}\left(s_{i}^{M}, w, r\right)$ if she is of the same type as her match, and $s^{D}\left(s_{i}^{M}, w, r\right)$ if she is not. Analogously, in the other subgame perfect equilibrium (corresponding to case $j$ ) the man saves $s_{j}^{M}$, and woman saves either $s^{S}\left(s_{j}^{M}, w, r\right)$ or $s^{D}\left(s_{j}^{M}, w, r\right)$. This is expressed in condition ( iii). The profit-maximizing conditions for the firms, and hence the demand for capital, are given by $(i i)$. In order to ensure market-clearing, it is necessary for a fraction $\lambda_{i}$ of the population to play the subgame perfect equilibrium corresponding to case $i$, and $\lambda_{j}$ to play the other; this is expressed by condition $(i)$.

\section{Some Numerical Examples}

To help clarify this model, we now present several numerical examples.

Consider a Cobb-Douglas production function

$$
f(k)=k^{\alpha}, \quad \text { for } 0<\alpha<1 \text {. }
$$

We also take $\beta=0.6$.

Example 7.1 Let $\alpha=0.4$. In this case, the steady state equilibrium is given by $w=$ 0.268884 and $r=1.33333$. This equilibrium falls in the province of case 3 , in which all women accept their marriage proposals, and also contribute to the marital consumption. 
It can be shown that, for the corresponding marriage game, the man's subgame perfect equilibrium saving is $s^{M}=0.0806653$. As a result, we know from equation (1) that when he marries a woman of his type, she will split their total resources between savings $s^{S}=0.188219$ and joint consumption $c^{S}=0.188219$. Similarly, equation (2) tells us that when his wife is of a different type, she will save $s^{D}=0.134442$ and they will also consume $c^{D}=0.134442$.

For this case, the total savings leads to a supply of capital (per efficiency unit of labor) of $k=0.134442$, as per equation (3). If we evaluate the profit maximizing conditions (4) at this capital stock, we obtain the wage and rental rates given above, and hence markets clear.

Notice that since couples always marry, a gender gap results. In particular, the average wage earned by women is $w(1+\beta) / 2=0.215107$, which represents a $20 \%$ wage gap.

Example 7.2 Now let $\alpha=0.2$. It can be verified that the steady state equilibrium is given by $w=0.622862$ and $r=0.544282$. This equilibrium corresponds to case 4 , where a woman marries only if it would not affect her income - that is, if she is of the same type as her match.

The man's subgame perfect equilibrium saving is $s^{M}=0.229524$. Thus, equation (1) implies that when he is matched to a woman of his own type, he marries and his wife divides their total resources equally between savings $s^{S}=0.373894$ and joint consumption $c^{S}=0.373894$. When the woman is not of his type, however, she refuses his proposal and so splits her wage equally between consumption today and savings $s^{D}=0.311431$. Consequently, the man can only consume his own savings, with accumulated interest.

The total savings now leads to a supply of capital (per efficiency unit of labor) of $k=$ 0.286093, as per equation (3). As before, if we evaluate the profit maximizing conditions (4) at this capital stock, we obtain the wage and rental rates given above, and hence markets clear. 
As we have already pointed out, in this case there is no gender gap.

Example 7.3 Now take $\alpha=0.3$. In this case there is no (pure) equilibrium as it has been defined. The problem is that case 4 occurs when the interest rate is so low that the men's savings are not sufficient to convince women who are not of their type to marry them. But with no need to convince these women, the men reduce their savings, which in turn lowers the capital stock and raises the interest rate, moving us back into the province of case 3 .

More precisely, suppose that there were a pure equilibrium, and that it fell into case 4, as in the previous example. In this case, the steady state capital stock would satisfy the following equation, obtained from (3):

$$
k=\frac{1}{2} s^{M}+\frac{1}{4}\left(s^{S}+s^{D}\right)
$$

Here $s^{M}$ is the optimal savings of the man when he is constrained to case $4,{ }^{15}$ and $s^{S}$ and $s^{D}$ are the corresponding women's savings, obtained from equations (1) and (2).

It can be shown that the only solution to this equation is $k=0.213825$; the corresponding wage and rental rates are $w=0.440672$ and $r=0.883242$. At these prices, however, the man's optimum savings corresponds to case 3, which implies that the subgame perfect equilibrium cannot correspond to case 4.

Similar arguments can be used to rule out the other cases.

This example demonstrates that a steady state pure equilibrium need not necessarily exist for all parameter values. This is a consequence of the fact that this solution concept requires all men to play the same strategy; namely to save the same amount. As we show below, when we allow for mixed equilibria - that is, for heterogeneity in men's behavior, equilibrium always exists. To illustrate this concept, we calculate a mixed equilibrium for the parameters of the previous example.

\footnotetext{
${ }^{15}$ That is, when he is constrained to save less than $\frac{(1-\beta) w}{r}$.
} 
Example 7.4 Once again, let $\alpha=0.3$. The equilibrium wage will be $w=0.485856$ and the rental rate $r=0.703341$.

The corresponding marriage game has two subgame perfect equilibria. In the first equilibrium, corresponding to case three, men save 0.276313 , which is exactly enough to persuade a woman of a different type to marry him, while women save either 0.340099 or 0.242928 , depending on whether they marry a husband of the same type or not. The second equilibrium corresponds to case four. Men choose to consume more during their youth and save only 0.183097. As a consequence, women find it worthwhile to accept a

man's proposal only when they are of the same type; in this case they save 0.340099. If they are of a different type, however, they prefer to build a career and earn a higher wage $w$, saving 0.242928 .

When a fraction 0.793047 of the agents play according to the first equilibrium and the rest of the population plays according to the second one, then the total savings per efficiency units of labor equals 0.29605. Once again, if we evaluate the profit maximizing conditions at this capital stock, we obtain the wage and rental rates given above and hence markets clear.

\section{Technology and the Social Patterns of Behavior}

This section describes the relationship between the technological parameters and the nature of the equilibria. These results are summarized in the following pictures.

In Figure 2 one can distinguish eight regions, corresponding to different types of competitive equilibria. For example, the rightmost region represents the parameter values $(\alpha, \beta)$ which result in a pure steady state equilibrium corresponding to case 1 . For small $\beta$, as we lower $\alpha$ we move to an equilibrium which mixes cases 1 and 2. Continuing to lower $\alpha$, the proportion of the population which plays as per case 1 eventually drops to zero and we are left in case 2 . As $\alpha$ drops further, the equilibria fall into mixed case 2 and 3 , then 


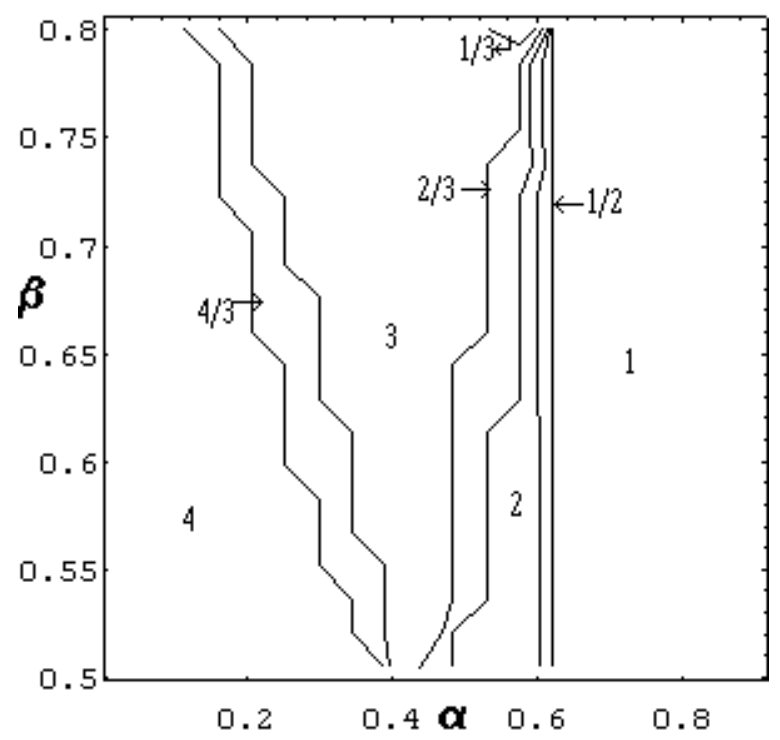

Figure 2: The Cases

pure case 3, mixed case 3 and 4 , and finally, for small $\alpha$, pure case $4 .{ }^{16}$

Figure 3, which gives the fraction of income saved by men in equilibrium, that is $s^{M}(w, w, r) / w$, helps further clarify how the production technology impacts on the social patterns of behavior. For large values of $\alpha$, we know from the previous figure that we are in case 1 and all women free-ride, so the joint consumption consists only of what the men have saved, plus accumulated interest; consequently men save one half of their income.

As we lower $\alpha$, the equilibrium interest rate also falls. ${ }^{17}$ This reduces the future value of the men's savings until the women, first those of the same type as their match (case 2) and then even those of different type (case 3), begin to contribute to the joint consumption out of their savings. As a result of the women's increasing contributions, the men need to save less and less out of their own income

\footnotetext{
${ }^{16}$ When $\beta$ is large, there is no pure equilibrium corresponding to case 2. Similarly, there are no mixed equilibria in which case 2 plays a role; instead, we find equilibria which mix cases 1 and 3 .

${ }^{17}$ Since the steady-state equilibrium $k$ goes up when $\alpha$ goes down, as it would in a standard Diamond (1965) model with the same production function and preferences.
} 


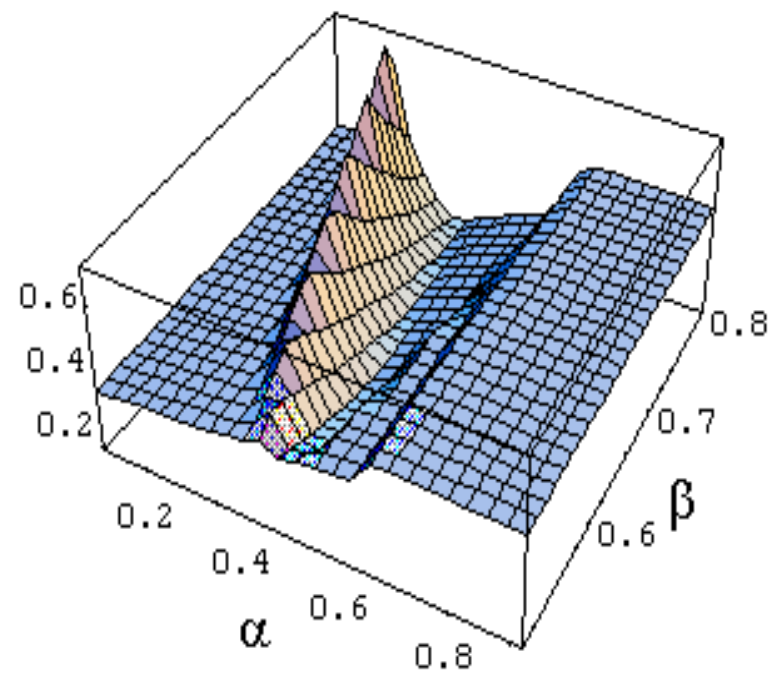

Figure 3: Male Saving Rate

For even lower $\alpha$, however, the future value of the men's saving is so small that they risk having their marriage proposal rejected if they are matched to a woman of a different type. In order to preserve the benefits of marriage, the men begin to sharply increase their saving, eventually exceeding even their case-1 level of $1 / 2$.

For very small $\alpha$, however, the men no longer consider it worthwhile to convince women of a different type to marry them. This corresponds to case 4 . Their savings in this case drop to lower than $1 / 2$, because they continue to benefit from the expectation of their wives' contributions should they be matched to women of their own type.

We can use this information to explain the effect that these transitions in behavior have on the relative welfare of men and women. The graph in Figure 4 gives the difference between the ex-ante equilibrium utility of a representative man and woman in this model. Note first of all that for values of $\alpha$ close to 1 , the women free-ride and are therefore better-off than the men. The general tendency of this graph is for the welfare of the men to be relatively greater the smaller the value of $\alpha$. In effect, what is occurring is that 


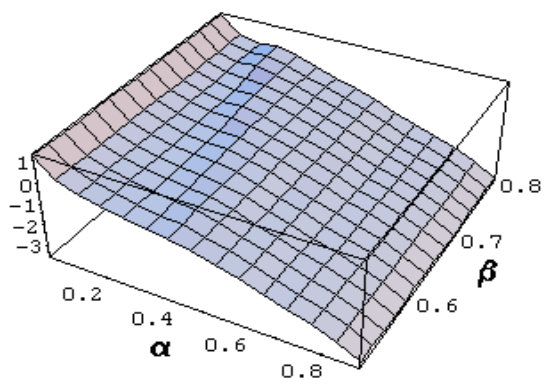

Figure 4: Utility Differential

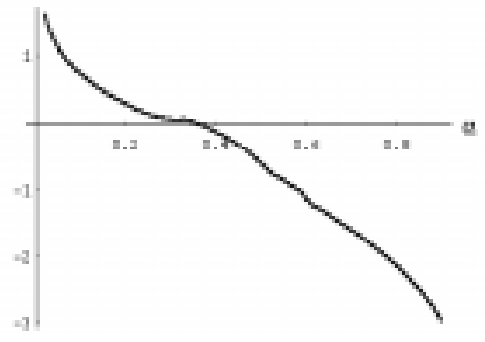

Figure 5: Cross-Section: $\beta=0.6$

as the interest rate drops, the interests of the women become more closely aligned with those of the men. This means that their ultimatum power has less "bite", and the men's first-mover advantage begins to dominate.

The reader may notice in Figure 5 that there is a small region for which the slope of this graph is nearly flat - this corresponds to the transition from case 3 to case 4 and is the outcome of two opposing effects. On the one hand, as we move from case 3 to 4 the men save less (since they no longer attempt to convince all of the women to marry them) which obviously hurts the women. On the other hand, however, this leads to a sharp drop in the equilibrium capital stock, and hence a higher interest rate, benefiting the women.

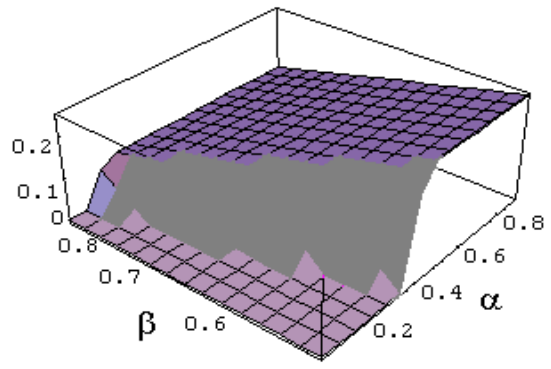

Figure 6: The Gender Gap

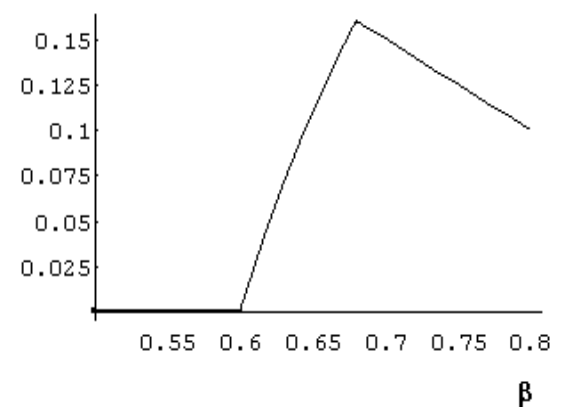

Figure 7: Cross-Section: $\alpha=0.25$

Finally, Figure 6 gives the percentage gender wage gap as a function of the parameter values of the model. For small $\beta$ we are in case 4 and only half of the women marry those who are of the same type as their match - consequently, the gender gap is zero. 
It is interesting to note that as we increase $\beta$ and labor becomes less firm-specific, the gender gap at first increases as we move to case 3 , since women find it less costly to marry someone of a different type. Eventually, however, when $\beta$ becomes sufficiently large the difference between types disappears and the gender gap must of course decrease to zero; in fact, we know that once we leave case 4 completely behind then the percentage gender gap is precisely $\frac{1}{2}-\frac{\beta}{2}$. This may be seen more clearly in Figure 7 , which gives a cross section of this graph for $\alpha=0.25$.

\section{Existence of Steady-State Equilibrium}

The following theorem shows that, under weak conditions, an equilibrium - either pure or mixed - always exists.

Theorem 9.1 Let $1 / 2<\beta<1$ and let $f(k)$ be a production function satisfying the following conditions:

1. $f(0)=0 ; f^{\prime}>0 ; f^{\prime \prime}<0$

2. $\lim _{k \rightarrow 0} f^{\prime}(k)=+\infty ; \lim _{k \rightarrow+\infty} f^{\prime}(k)=0$

3. $\lim _{k \rightarrow 0}-\frac{2+\beta}{3+\beta} k f^{\prime \prime}(k)>1$.

Then a competitive equilibrium exists.

Conditions 1 and 2 are standard. Condition 3 will ensure that the aggregate saving function (per efficiency unit of labor) has a slope greater than 1 at the origin. ${ }^{18}$ Notice that the Cobb-Douglas production function $f(k)=k^{\alpha}$ satisfies these conditions for $0<\alpha<1$.

Proof : The idea of the proof is as follows. If there is no pure equilibrium, then we show that there must exist a capital stock $k^{*}$, with its corresponding wage and rental rates,

\footnotetext{
${ }^{18}$ Similar conditions appear in Galor and Ryder (1989).
} 
for which there are (at least) two subgame perfect equilibria of the associated marriage game. Were the entire population to play one of these equilibria, the resulting aggregate savings would exceed $k^{*}$, whereas at the other equilibrium the savings would be less than $k^{*}$. One can then construct a mixed equilibrium by having some fraction of the population play one of the subgame perfect equilibria and the remainder play the other. This fraction is chosen so that the supply of capital, that is the aggregate savings, is precisely equal to the demand for capital $k^{*}$.

We now begin the formal proof.

If a pure equilibrium exists, then we are done. Now assume that no such equilibrium exists.

We define the "indirect" (expected) utility function $U(k)$ for a representative man. This is the maximal expected utility a man can achieve when the wage is given by $w(k)=$ $f(k)-k f^{\prime}(k)$ and the rental rate is $r(k)=f^{\prime}(k)$, and the women respond optimally to the man's actions. The reader may recall that each level of savings $s^{M}$ on the part of the man leads to one of four cases, corresponding to different modes of behavior on the part of the women. Thus the man may be viewed as solving each of these sub-problems and choosing the case which gives him the highest utility. Thus, if we let $U^{i}(k)$, for $i=1, \ldots, 4$ denote the indirect utility functions when the man is constrained to choose a level of saving consistent with case $i$, then

$$
U(k)=\max \left\{U^{1}(k), U^{2}(k), U^{3}(k), U^{4}(k)\right\} .
$$

We also let $\mathcal{K}^{i}=\left\{k \in \mathbb{R}_{++} \mid U(k)=U^{i}(k)\right\}, \quad i=1, \ldots, 4$ denote the set of all capital stock $k$ for which the man chooses case $i$. Within each case, the Theorem of the Maximum implies that each $U^{i}(k)$ is continuous. Therefore, $U(k)$ is itself continuous and each $\mathcal{K}^{i}$ is a closed set.

In addition, on $\mathcal{K}^{i}$, let $\mathcal{S}^{i}(k)$ be the function which associates to each capital stock $k$ the corresponding per-efficiency units aggregate subgame perfect equilibrium savings. ${ }^{19}$ Note

\footnotetext{
${ }^{19}$ For example, $\mathcal{S}^{1}(k)=\frac{2}{3+\beta} \frac{w(k)}{2}+\frac{1}{3+\beta}(w(k)+\beta w(k))$.
} 
that since we have assumed that there is no pure equilibrium, there is no $i$ and $k^{*} \in \mathcal{K}^{i}$ for which $\mathcal{S}^{i}\left(k^{*}\right)=k^{*}$.

Finally, we can define

$$
\mathcal{S}^{-}=\left\{k \mid k \in \mathcal{K}^{i} \text { and } k>\mathcal{S}^{i}(k), \text { for some } i \in\{1, \ldots, 4\}\right\}
$$

and

$$
\mathcal{S}^{+}=\left\{k \mid k \in \mathcal{K}^{i} \text { and } k<\mathcal{S}^{i}(k), \text { for some } i \in\{1, \ldots, 4\}\right\}
$$

We can now prove the following lemma.

Lemma $9.2 \mathcal{S}^{+}$and $\mathcal{S}^{-}$are both nonempty.

Proof : To prove that $\mathcal{S}^{+} \neq \emptyset$, we show that there exists $k \in \mathcal{K}^{1}$ such that $\mathcal{S}^{1}(k)>k$.

We first show that for $k$ sufficiently small, $k \in \mathcal{K}^{1}$. Intuitively, this is because for small $k$, the rental rate is sufficiently high so that the future value of the men's saving is more than enough to make all women free ride. More precisely, note that women will never contribute more than $w / 2$ to the joint consumption. Therefore, given that the man has $\log$-utility, he will never want to consume less than $\frac{w+w /(2 r)}{2}$ in the first period of his life, and hence will save at least $\frac{w}{2}\left(1-\frac{r}{2}\right)$. Consequently, for $k$ sufficiently small, and hence $r$ sufficiently large, the future value $s^{M} r$ of the man's optimal saving will exceed $w$. This implies that man's solution falls into case 1.

To see that $\mathcal{S}^{-}$is nonempty, note that for $k$ sufficiently large, we know that $k>f(k)$. But $f(k)>w$, and since agents cannot save more than they earn, it follows that $k$ is larger than the aggregate saving (per efficiency unit).

We now continue with the proof of the theorem. We require the following lemma.

Lemma $9.3 \mathcal{S}^{+} \cap \mathcal{S}^{-} \neq \emptyset$ 
Proof: There are two cases to consider.

(a) $\mathcal{S}^{+}$and $\mathcal{S}^{-}$are both open sets in $\mathbb{R}_{++}$.

Since by assumption there is no pure equilibrium, $\mathcal{S}^{+} \cup \mathcal{S}^{-}=\mathbb{R}_{++}$. Since $\mathbb{R}_{++}$is a connected set, it follows that $\mathcal{S}^{+} \cap \mathcal{S}^{-} \neq \emptyset$.

(b) At least one of the sets $\mathcal{S}^{+}$and $\mathcal{S}^{-}$is not open in $\mathbb{R}_{++}$.

Without loss of generality, assume that $\mathcal{S}^{-}$is not open. Choose $k^{*} \in \mathcal{S}^{-}$which is not interior. From the definition of $\mathcal{S}^{-}$, there exists a case $i$ for which $k^{*} \in \mathcal{K}^{i}$. Since $k^{*}$ is not interior, we can find a sequence $\left\{k_{n}\right\} \rightarrow k^{*}$ with $k_{n} \in \mathcal{S}^{+}$. Moreover, since there are only finitely many cases, we can assume without loss of generality that there exists a case $j$ such that $k_{n} \in \mathcal{K}^{j}$ for all $n$. Note that from the definitions of $\mathcal{S}^{+}$and $\mathcal{S}^{-}, j \neq i$.

Since $\mathcal{K}^{j}$ is closed, this implies that $k^{*} \in \mathcal{K}^{j}$ as well. From the Theorem of the Maximum, the function $\mathcal{S}^{j}$ is continuous. So $\left\{k_{n}\right\} \in \mathcal{S}^{+}$implies that $k^{*}-\mathcal{S}^{j}\left(k^{*}\right) \leq 0$. But since we have assumed that there is no pure equilibrium, we must have $k^{*}-\mathcal{S}^{j}\left(k^{*}\right)<0$ and so $k^{*} \in \mathcal{S}^{+}$as well.

From the lemma above, we know that $\mathcal{S}^{+} \cap \mathcal{S}^{-} \neq \emptyset$. That is, there exists $k^{*}$, and $i \neq j$, such that $k^{*}-\mathcal{S}^{j}\left(k^{*}\right)<0<k^{*}-\mathcal{S}^{i}\left(k^{*}\right)$. To construct a mixed equilibrium based on $k^{*}$ we must simply find weights $\lambda_{i}+\lambda_{j}=1$ such that when a fraction $\lambda_{i}$ of the population plays the subgame perfect equilibrium associated with case $i$ and $\lambda_{j}$ plays that associated with case $j$, the resulting aggregate savings (per efficiency units) equals the demand for capital $k^{*}$. This is immediate, however, since the aggregate savings is continuous as a function of $\left(\lambda_{i}, \lambda_{j}\right)$ and is equal to $\mathcal{S}^{i}\left(k^{*}\right)<k^{*}$ when $\left(\lambda_{i}, \lambda_{j}\right)=(1,0)$ and to $\mathcal{S}^{j}\left(k^{*}\right)>k^{*}$ when $\left(\lambda_{i}, \lambda_{j}\right)=(0,1)$ 


\section{References}

Bergstrom, T. C. (1995, June). A survey of theories of the family. Forthcoming, Journal of Economic Literature.

Bergstrom, T. C. and M. Bagnoli (1993, February). Courtship as a waiting game. Journal of Political Economy 101(1), 185-202.

Chattopadhyay, A. (1996). Gender Differences in the Effect of Family Migration on Occupational Mobility in Malaysia. Ph. D. thesis, Brown University.

Diamond, P. A. (1965, December). National debt in a neoclassical growth model. American Economic Review 55(5), 1126-1150.

Echevarria, C. and A. Merlo (1995, August). Gender differences in education in a dynamic household bargaining model. Research Department Staff Report 195, Federal Reserve Bank of Minneapolis.

Engers, M. and S. Stern (1996, March). Long-term care and family bargaining. Mimeo., University of Virginia.

Francois, P. (1996, February). A theory of gender discrimination based on the household. Discussion Paper 929, Institute for Economic Research, Queen’s University.

Galor, O. and H. E. Ryder (1989, December). Existence, uniqueness and stability of equilibrium in an overlapping - generations model with productive capital. Journal of Economic Theory 49(2), 360-375.

Galor, O. and D. N. Weil (1996, June). The gender-gap, fertility, and growth. American Economic Review 86(3), 374-387.

Goldin, C. (1986, January). Monitoring costs and occupational segregation by sex: A historical analysis. Journal of Labor Economics 4 (1), 1-27.

Gunderson, M. (1989, March). Male-female wage differentials and policy responses. Journal of Economic Literature 5\%, 46-72. 
Lazear, E. P. and S. Rosen (1990, January). Male-female wage differentials in job ladders. Journal of Labor Economics 8(1), S106-S123.

Mahony, R. (1995). Kidding Ourselves: Breadwinning, Babies, and Bargaining Power. New York: Basic Books.

Manser, M. and M. Brown (1980, February). Marriage and household decision theory - a bargaining analysis. International Economic Review 21(1), 21-34.

McElroy, M. and M.-J. Horney (1981, June). Nash-bargained household decisions: Toward a generalization of the theory of demand. International Economic Review 22(2), $333-349$.

Mincer, J. (1978, October). Family migration decisions. Journal of Political Economy $86(5), 749-73$.

Osborne, M. J. and A. Rubinstein (1994). A Course in Game Theory. Cambridge, Massachusetts: The MIT Press.

Payne, D. M. and J. T. Warner (1992, June). Tied migration and returns to human capital: The case of military wives. Social Science Quarterly 73(2), 324-39.

Rosenzweig, M. R. and O. Stark (1989, August). Consumption smoothing, migration, and marriage: Evidence from rural india. Journal of Political Economy 97(4), 90526.

Rothschild, M. and J. Stiglitz (1982). A model of employment outcomes illustrating the effect of the structure of information on the level and distribution of incomes. Economics Letters 10, 231-236.

United Nations Department of International Economic and Social Affairs (1990). Patterns of First Marriage: Timing and Prevalence. New York: United Nations Department of International Economic and Social Affairs.

U.S. Bureau of the Census (1995). Statistical Abstract of the United States: 1995. Washington, DC: U.S. Bureau of the Census. 